\title{
Induction of autophagy through the activating transcription factor 4 (ATF4)-dependent amino acid response pathway in maternal skeletal muscle may function as the molecular memory in response to gestational protein restriction to alert offspring to maternal nutrition
}

\author{
Huan Wang ${ }^{1}$, Gabriel J. Wilson ${ }^{2} \dagger$, Dan Zhou ${ }^{1} \neq$, Stéphane Lezmi ${ }^{2,3}$, Xiuwen Chen ${ }^{1}$, Donald K. Layman ${ }^{1,2}$ \\ and Yuan-Xiang $\operatorname{Pan}^{1,2,4 *}$ \\ ${ }^{1}$ Department of Food Science and Human Nutrition, College of Agricultural, Consumer and Environmental Sciences, \\ University of Illinois at Urbana-Champaign, 905 South Goodwin Avenue, Urbana, IL 61801, USA \\ ${ }^{2}$ Division of Nutritional Sciences, College of Agricultural, Consumer and Environmental Sciences, University of Illinois at \\ Urbana-Champaign, 905 South Goodwin Avenue, Urbana, IL 61801, USA \\ ${ }^{3}$ Department of Pathobiology, College of Veterinary Medicine, University of Illinois at Urbana-Champaign, 2838 VMBSB, \\ M/C 002, Urbana, IL 61802, USA \\ ${ }^{4}$ Illinois Informatics Institute, College of Agricultural, Consumer and Environmental Sciences, University of Illinois at \\ Urbana-Champaign, 461 Bevier Hall, MC-182, 905 South Goodwin Avenue, Urbana, IL 61801, USA
}

(Submitted 25 November 2014 - Final revision received 18 April 2015 - Accepted 27 May 2015 - First published online 22 July 2015)

\section{Abstract}

The aim of the present study was to investigate the mechanistic basis of protein deficiency during pregnancy in mother that is transduced to offspring. To this end, timed-pregnant Sprague-Dawley rats were fed either a control (20\% of energy from protein) or low-protein (LP, $8 \%$ of energy from protein) diet during gestation. Tissues were collected after delivery from rat dams, and skeletal muscle was collected at postnatal day 38 from the offspring. Quantitative RT-PCR and Western blot analyses were performed to determine mRNA and protein levels. Histological analysis was performed to evaluate myofibre size. LP dams gained significantly less weight during pregnancy, developed muscle atrophy, and had significantly lower circulating threonine and histidine levels than control dams. The mRNA expression of the well-known amino acid response (AAR) pathway-related target genes was increased only in the skeletal muscle of LP dams, as well as the protein expression levels of activating transcription factor 4 (ATF4) and phosphorylated eukaryotic translation initiation factor $2 \alpha$ (p-eIF $2 \alpha$ ). The mRNA expression of autophagy-related genes was significantly increased in the skeletal muscle of LP dams. Moreover, the mRNA expression of genes involved in both AAR and autophagy pathways remained elevated and was memorised in the muscle of LP offspring that consumed a post-weaning control diet. Additionally, the LP diet increased an autophagy marker, microtubule-associated proteins 1A/1B light chain 3B (LC3B) protein expression in the skeletal muscle of rat dams, consistent with the initiation of autophagy. The LP diet further increased ATF 4 binding at the predicted regions of AAR and autophagy pathway-related genes. Increased binding of ATF 4 unveils the crucial role of ATF4 in the activation of autophagy in response to protein restriction. Our data suggest that molecular changes in maternal muscle are memorised in the offspring long after gestational protein restriction, reinforcing the role of maternal signalling in programming offspring health.

Key words: Genes: Autophagy: Pregnancy: Protein restriction: Transcription factors

During pregnancy, maternal macronutrient metabolism changes to adapt to the needs of the developing fetus ${ }^{(1)}$. Although changes in glucose metabolism occur in parallel with increasing energy demands, adaptation of protein metabolism - through the accumulation and breakdown of protein stores - is an essential component of maternal adaptation to pregnancy ${ }^{(2)}$. Pregnancy is often associated with hypoaminoacidaemia and urinary $\mathrm{N}$ losses during fasting, which is evident early in gestation and persists throughout pregnancy ${ }^{(3,4)}$. The major source of urea $\mathrm{N}$ during pregnancy is peripheral

Abbreviations: AAR, amino acid response; Atf3, activating transcription factor 3; Asns, asparagine synthetase; ATF4, activating transcription factor 4; Chop, C/EBP homology protein; eIF2 $\alpha$, eukaryotic translation initiation factor $2 \alpha$; LP, low protein; NFDM, non-fat dry milk; p-eIF2 $\alpha$, phosphorylated eukaryotic translation initiation factor $2 \alpha$.

* Corresponding author: Y.-X. Pan, fax +1 217265 0925, email yxpan@illinois.edu

†Present address: Maximum Human Performance (MHP), West Caldwell, NJ, USA.

‡Present address: Mayo Clinic, Rochester, MN, USA. 
(muscle) release of amino acids $^{(2)}$, and Kalkhoff et al. ${ }^{(5)}$ showed a positive correlation between total circulating amino acid concentrations and neonatal birth weight. The role of maternal protein balance in both maternal health and gestational outcomes highlights the importance of the maternal diet. Because of this, the low-protein (LP) rodent model is one of the best-characterised developmental programming models, demonstrating that even a marginal protein restriction ( $8 \%$ of energy from protein) during pregnancy has physiological impacts on both the mother and the offspring ${ }^{(6)}$.

Dietary protein restriction in experimental animals and cellculture models produces numerous metabolic responses, including the activation of the amino acid response (AAR) pathway ${ }^{(7)}$. AAR pathway activation in response to amino acid limitation occurs largely through the signal transductionmediated altered transcriptional activity of specific genes including Asns (asparagine synthetase) ${ }^{(8)}$, Atf3 (activating transcription factor 3$)^{(9)}$ and Chop (C/EBP homology protein $)^{(10,11)}$. The activation of the AAR pathway requires the phosphorylation of eukaryotic translation initiation factor $2 \alpha$ (eIF $2 \alpha$ ) by general control non-derepressible 2 (GCN2) kinase, leading to a decrease in global protein synthesis ${ }^{(12)}$ but an increase in the synthesis of activating transcription factor 4 (ATF4) protein $^{(12-14)}$, which activates multiple stress-induced genes, including genes containing an AAR element ${ }^{(15)}$. Therefore, ATF4 appears to serve as a master regulator of the AAR pathway, further supported by observations that ATF 4 binds at the promoter regions of Asns ${ }^{(16)}$ and Atf $^{(17)}$.

Due to the well-characterised and direct relationship between protein restriction (even marginally) and the activation of ATF4 target genes, the AAR pathway has served as a hallmark marker of dietary protein deficiency. However, skeletal muscle accounts for over $40 \%$ of body protein and is a critical site for labile protein in response to nutritional stress, and the autophagic/lysosomal pathway has also been associated with protein mobilisation in skeletal muscle ${ }^{(18)}$. Therefore, autophagy could potentially serve as an additional nutrient-sensing mechanism in response to protein deficiency. Autophagy, primarily known as macroautophagy in cellular metabolism, involves cell degradation of unnecessary or dysfunctional cellular components through the lysosomal machinery, and has been highly associated with myopathy ${ }^{(19,20)}$. LC3 and BNIP3 have been shown to be key proteins during the process of autophagy ${ }^{(21)}$, and ATF4, the key regulatory protein within the AAR pathway that has a role in muscle dystrophy induced by fasting ${ }^{(22,23)}$, has also recently been associated with autophagy ${ }^{(22,24)}$.

Gestational protein restriction activates the placental AAR pathway, which is associated with long-term growth restriction in the offspring ${ }^{(25)}$. However, the response and potential contribution of maternal metabolism in this process is unknown. Therefore, the purpose of the present study was to investigate the molecular response of maternal tissues to gestational protein restriction. Specifically, we first focused on the AAR pathway as the classic marker of protein restriction, and then investigated the potential role of ATF 4 within the autophagy pathway, as a potential physiological consequence of gestational protein deficiency. We also relied on our study in which gestationally LP diet-exposed offspring were growth-restricted adults, despite consuming a control diet after weaning, to determine whether gestational protein restriction was still evident at the molecular level in the muscle of these offspring at postnatal day 38. Understanding the adaptations that occur within maternal metabolism in response to protein restriction would provide valuable insight into our understanding of how the maternal tissue/placental/ fetal axis contributes to the programming of chronic diseases in response to maternal protein deficiency.

\section{Experimental methods}

\section{Animals and diets}

Timed-pregnant Sprague-Dawley rats were obtained from Charles River Laboratories and randomly assigned to one ( $n$ 6) of two isoenergetic, modified AIN-93 diets ${ }^{(26)}$ (Research Diet, Inc.; Table 1). Study 1 included the following diets: control diet (20\% of energy from protein, 64\% of energy from carbohydrate and $16 \%$ of energy from fat) or low-protein diet (LP; $8 \%$ of energy from protein, $76 \%$ of energy from carbohydrate and $16 \%$ of energy from fat) from day 2 of gestation until the end of gestation. Study 2 included the following diets: control diet (18\% of energy from protein, $66 \%$ of energy from carbohydrate and $16 \%$ of energy from fat) or LP diet (9\% of energy from protein, $75 \%$ of energy from carbohydrate and $16 \%$ of energy from fat) from day 2 of gestation until the end of gestation ${ }^{(25)}$. Rat dams in study 2 consumed a control diet during lactation ${ }^{(25,27)}$, and all offspring consumed the same control diet after weaning (postnatal day 21) until postnatal day 38. The rats were housed individually in standard polycarbonate cages in a humidityand temperature-controlled environment at a $12 \mathrm{~h}$ light-12 $\mathrm{h}$ dark cycle. Body weights and food intake were recorded every other day.

Post-delivery dams were fasted for $8 \mathrm{~h}$ and then euthanised by $\mathrm{CO}_{2}$ for $20 \mathrm{~s}$ before decapitation to collect blood for plasma and serum preparation. Visceral adipose tissue, gastrocnemius muscle and liver samples from dams in study 1 were harvested

Table 1. Composition of the experimental diets*

\begin{tabular}{lccc}
\hline Ingredients $(\mathrm{g} / \mathrm{kg})$ & $\begin{array}{c}\text { Control } \\
(20 \% \text { of } \\
\text { energy })\end{array}$ & $\begin{array}{c}\text { Low protein } \\
(9 \% \text { of } \\
\text { energy })\end{array}$ & $\begin{array}{r}\text { Low protein } \\
(8 \% \text { of } \\
\text { energy })\end{array}$ \\
\hline Casein & 200 & 90 & 80 \\
L-Cys & 3 & $1 \cdot 2$ & $1 \cdot 2$ \\
Maize starch & 397 & 509 & 519 \\
Maltodextrin 10 & 132 & 132 & 132 \\
Sucrose & 100 & 100 & 100 \\
Cellulose, BW200 & 50 & 50 & 50 \\
Soyabean oil & 70 & 70 & 70 \\
Mineral mix S10026† & 35 & 35 & 35 \\
Vitamin mix V10001† & 10 & 10 & 10 \\
Choline bitartrate & 2.5 & 2.5 & 2.5 \\
TBHQ & 0.014 & 0.014 & 0.014 \\
Total & 1000 & 1000 & 1000 \\
\hline
\end{tabular}

TBHQ, tertiary butylhydroquinone.

* Modified AIN-93 G diet.

† Vitamin mix V10001 and mineral mix S10026 were obtained from Dyets, Inc. 
and snap-frozen in liquid $\mathrm{N}_{2}$ and stored at $-80^{\circ} \mathrm{C}$ for future analyses. Skeletal muscle from the offspring was collected on $38 \mathrm{~d}$ after birth in study 2 . All experiments were conducted in accordance with the National Institutes of Health Guide for the Care and Use of Laboratory Animals ${ }^{(28)}$, and approved by the University of Illinois at Urbana-Champaign Institutional Animal Care and Use Committee.

\section{Plasma measurements}

Maternal plasma obtained from trunk blood was immediately centrifuged at $800 \mathrm{~g}$ for $20 \mathrm{~min}$ at $4^{\circ} \mathrm{C}$. Plasma samples were stored at $-70^{\circ} \mathrm{C}$ until further analysis. Plasma free amino acid concentrations were measured by HPLC using a Waters 2475 fluorescence detector (Waters) ${ }^{(29)}$. Amino acid hydrolysate standard was purchased from the same company (WAT088122). Analyses included essential amino acids (Leu, Ile, Lys, Met, Val and Thr) and non-essential amino acids (His, Glu, Asp, Pro, Tyr, Ala, Arg, Ser and Gly).

\section{Muscle fibre diameter}

From each treatment group, six frozen muscle samples were embedded in Tissue-Tek OCT compound (VWR) and cut into $5 \mu \mathrm{m}$ thickness cross-sectionally using a Leica CM3050 S cryostat (Leica Microsystems, Inc.) at $-20^{\circ} \mathrm{C}$, as reported previously $^{(30,31)}$. All sections were fixed in $70 \%$ ethanol and stained with haematoxylin and eosin (Newcomer Supply). Histopathological examination was performed blindly using light microscopy by a certified pathologist (S. L.). Slides were scanned using a NanoZoomer Digital Pathology System with a magnification of $20 \times$ (Hamamatsu Photonics K.K.), and image analysis was performed using ImageJ software. From each section, three independent regions were selected for quantification. The diameters of at least sixty myofibres per independent region were measured using the lesser diameter method, as described previously ${ }^{(23)}$.

\section{RNA isolation and two-step real-time quantitative $P C R$}

Total RNA was isolated from the visceral adipose tissue, gastrocnemius muscle, liver and blood of dams, and from the gastrocnemius muscle of the offspring using TRI-Reagent (Sigma-Aldrich), according to the manufacturer's instructions. RNA concentration was analysed by a Bio-Rad spectrophotometer (Bio-Rad Laboratories, Inc.) at $260 \mathrm{~nm}$. Total mRNA $(2 \mu \mathrm{g})$ was used for complementary DNA synthesis by the High Capacity cDNA Reverse transcription Kit (Applied Biosystems) with a DNA 2720 Thermal Cycler (Applied Biosystems). The programme was as follows: $25^{\circ} \mathrm{C}$ for $10 \mathrm{~min}, 37^{\circ} \mathrm{C}$ for $120 \mathrm{~min}$ and $85^{\circ} \mathrm{C}$ for $5 \mathrm{~s}$. After synthesis, $25 \mathrm{ng}$ of complementary DNA were analysed using real-time quantitative PCR, and gene expression was assessed using the $2 \times$ Perfecta SYBR Green Fast Master Mix (Quanta BioSciences, www.vwr.com) with a 7300 Real-Time PCR System (Applied Biosystems). Primer sequences used in the experiment are listed in online Supplementary Table S1, and were designed by Vector NTI software (Invitrogen Corporation) and synthesised by Integrated
DNA Technologies (www.idtdna.com). The reaction was as follows: $95^{\circ} \mathrm{C}$ for $15 \mathrm{~min}, 95^{\circ} \mathrm{C}$ for $15 \mathrm{~s}$ and $60^{\circ} \mathrm{C}$ for $60 \mathrm{~s}$ in forty cycles. After amplification, dissociation curves were generated by stepwise increases from 55 to $95^{\circ} \mathrm{C}$ to ensure that a specific product was amplified in the reaction. Standard curves with a slope of $-3.30(\operatorname{sem} 0.20)$ and $R^{2} \geq 0.99$ were accepted. The following tissue-specific housekeeping genes whose expression was not affected by the treatment were used to normalise all mRNA data: 605 ribosomal protein $(L 7 a)$ in rat dams' adipose tissue and in offspring skeletal muscle; TATA-binding protein $(T b p)$ in rat dams' liver and blood; $\beta$-actin $(A c t b)$ in rat dams' skeletal muscle.

\section{Protein isolation and Western blotting}

Frozen gastrocnemius muscle $(200 \mathrm{mg})$ was ground in liquid $\mathrm{N}_{2}$ and suspended in $500 \mu \mathrm{l}$ of protein lysis buffer $(0 \cdot 125 \mathrm{M}-$ Tris- $\mathrm{HCl}, \mathrm{pH} 6 \cdot 8,1 \%$ SDS, $0.04 \%$ bromophenol blue and $20 \%$ glycerol, v/v) with $1 \times$ proteinase inhibitor (Roche Applied Science) and phosphatase inhibitor cocktail 1 and 2 (Sigma-Aldrich). Samples were then sonicated with twentyfive pulses at a power setting of 2 (Fisher Scientific Model 100 Sonic Dismembrator). Diluted protein samples $(20 \mu \mathrm{g})$ were size-fractionated on a $12 \%$ Tris $-\mathrm{HCl}$ polyacrylamide gel and transferred onto a polyvinyl difluoride (PVDF) membrane (Bio-Rad Laboratories, Inc.) at $0.3 \mathrm{~A}$, according to the wet transfer protocol. To investigate ATF4 (CAMP response element-binding protein 2; CREB2) protein expression, the PVDF membrane was incubated with blocking solution $(10 \%(\mathrm{w} / \mathrm{v})$ non-fat dry milk (NFDM) $)$ in TBS/T (20 mMTris-HCl, pH 7.6, $137 \mathrm{~mm}-\mathrm{NaCl}$ and $0 \cdot 1 \%$ (v/v) Tween-20) for $1 \mathrm{~h}$ at room temperature. A rabbit polyclonal antibody against ATF4 (sc-200; Santa Cruz) was diluted at 1:1500 in the blocking solution with $10 \%$ NFDM and incubated with the membrane for $3 \mathrm{~h}$ at room temperature before washing ( $5 \mathrm{x}$ ) with $5 \%$ NFDM in TBS/T for 5 min. A goat anti-rabbit HRP-conjugated secondary antibody (Kirkegaard\&Perry Laboratories) was diluted at 1:10000 in the blocking solution containing 5\% NFDM and incubated with the membrane for $1 \mathrm{~h}$ at room temperature. After washing for $5 \mathrm{~min}$ in the blocking solution $(5 \times)$ containing $3 \%(\mathrm{w} / \mathrm{v}) \mathrm{NFDM}$, the membrane was exposed to the enhanced chemiluminescence reagent Super Signal West Dura (Thermo Fisher Scientific). Signals from the membrane were detected and quantified by the ChemiDoc XRS Imaging System (Bio-Rad). $\beta$-Actin (SC-1616-R; Santa Cruz) was used as a loading control for the protein expression of ATF4. Total eIF2 $\alpha$ (9722S; Cell Signaling Technology, Inc.) was used as a loading control for phosphorylated eukaryotic translation initiation factor $2 \alpha$ (p-eIF2 $\alpha$ ) (9721L; Cell Signaling Technology, Inc.). The condition for detecting the p-eIF2 $\alpha$ protein was as follows: 5\% NFDM in TBS/T solution for $1 \mathrm{~h}$ of blocking and 1:1000 diluted primary antibody against p-eIF $2 \alpha$ for $3 \mathrm{~h}$ of incubation at room temperature. A blocking buffer of $1 \%$ NFDM in TBS/T solution was used for washing (5x) for $5 \mathrm{~min}$ followed by incubation with a secondary monoclonal goat-anti-rabbit antibody (Cell Signaling Technology, Inc.) for $1 \mathrm{~h}$. Furthermore, $1 \% \mathrm{NFDM}$ in TBS/T solution was used for the subsequent 5 min washing $(5 x)$. 


\section{Chromatin immunoprecipitation}

Chromatin immunoprecipitation analysis was performed according to a modified protocol ${ }^{(16)}$. In brief, $200 \mathrm{mg}$ frozen gastrocnemius muscle was ground in liquid $\mathrm{N}_{2}$ and suspended in PBS. Protein-DNA cross-linking was performed by $1 \%$ formaldehyde in PBS solution for $10 \mathrm{~min}$, and the reaction was stopped by $2 \mathrm{M}$-glycine to a final concentration of $0 \cdot 125 \mathrm{M}$. Nuclei were collected after nuclei swelling buffer treatment (5 mm-piperazine-N, $\mathrm{N}^{\prime}$-bis, 2-ethanesulfonic acid (PIPES), $\mathrm{pH}$ $8.0,85 \mathrm{~mm}-\mathrm{KCl}, 0.5 \% \mathrm{NP} 40)$ and lysed in SDS lysis buffer (50 mm-Tris-HCl, pH 8.1, 10 mm-EDTA, 1\% SDS) containing protease inhibitor and phosphatase inhibitor cocktails. Crosslinked chromatin was sheered and homogenised on ice by a Sonic Dismembrator (Model F100; Fisher Scientific) for $40 \mathrm{~s}$ at a power setting of 5 with a 2 min cooling interval between each burst, with a total of five bursts. The average length of sonicated chromatin was approximately $500 \mathrm{bp}$, and cell debris was removed by centrifugation at $13000 \boldsymbol{g}$ for $10 \mathrm{~min}$ at $4^{\circ} \mathrm{C}$. Sheared chromatin was diluted to $10 \mathrm{ml}$ with chromatin immunoprecipitation dilution buffer. A solution of $1 \mathrm{ml}$ diluted chromatin was incubated overnight with $2 \mu \mathrm{g}$ antibody at $4^{\circ} \mathrm{C}$. The chromatin-antibody complex was precipitated with $60 \mu \mathrm{l}$ of $50 \%$ slurry of pre-blocked protein G-agarose beads (Millipore) for $2 \mathrm{~h}$ at $4^{\circ} \mathrm{C}$. A normal rabbit IgG was used as a negative control. The supernatant from the incubated $\operatorname{IgG}$ was used as the input DNA for each sample. The protein
G-agarose beads were sequentially washed with $1 \mathrm{ml}$ each of the following solutions: low salt $(20 \mathrm{~mm}-$ Tris- $\mathrm{HCl}, \mathrm{pH} 8 \cdot 0$, $0 \cdot 1 \%$ SDS, 2 mm-EDTA, 150 mm-NaCl, $1 \%$ Triton X-100), high salt (20 mm-Tris-HCl, pH 8.0, $0 \cdot 1 \%$ SDS, 2 mm-EDTA, $500 \mathrm{~mm}-\mathrm{NaCl}, 1 \%$ Triton X-100), LiCl (10 mm-Tris-HCl, pH 8.0, 0.25 mm-LiCl, $1 \%$ NP40, 1 mm-EDTA, $1 \%$ sodium deoxycholate); twice with Tris-EDTA ( $\mathrm{pH} 8 \cdot 0$ ). The antibody/protein/DNA complexes were eluted twice by the addition of $250 \mu$ l elution buffer ( $1 \%$ SDS and $\left.50 \mathrm{~mm}-\mathrm{NaHCO}_{3}\right)$ at $37^{\circ} \mathrm{C}$ for $15 \mathrm{~min}$ each time. Reverse cross-linking was performed with $20 \mu \mathrm{l}$ of $5 \mathrm{M}-\mathrm{NaCl}$ and $1 \mu \mathrm{g}$ of RNase A at $65^{\circ} \mathrm{C}$ for $5 \mathrm{~h}$. Chromatin DNA was purified using the QIAPrep Miniprep Kit (Qiagen) after proteinase $\mathrm{K}$ digestion. Results are expressed as the average ratio of IgG to input DNA. The antibodies are listed in online Supplementary Table S2.

\section{Bioinformatics}

Transcription factor binding sites were identified by TFSE$\mathrm{ARCH}^{(32)}$ and MatInspector ${ }^{(33)}$ programs. All sequences were derived from the promoter sequence retrieval database EIDorado 02-2010 (Genomatix). The motif of the AAR element and CAMP response element-binding protein (CREB) was scanned with the Gene2Promoter large-scale program in the Genomatix software suite GEMS Launcher version 2.7 to evaluate any genes containing AAR element and CREB binding motifs within the rat genome ${ }^{(33)}$. The promoter sequences were

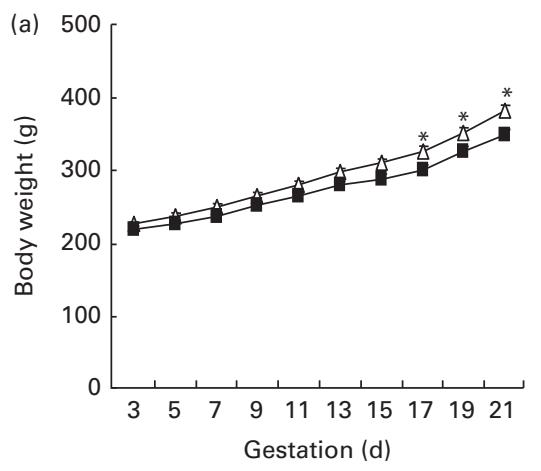

(c)

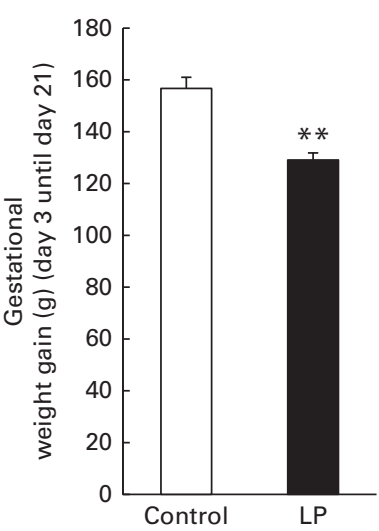

(d)

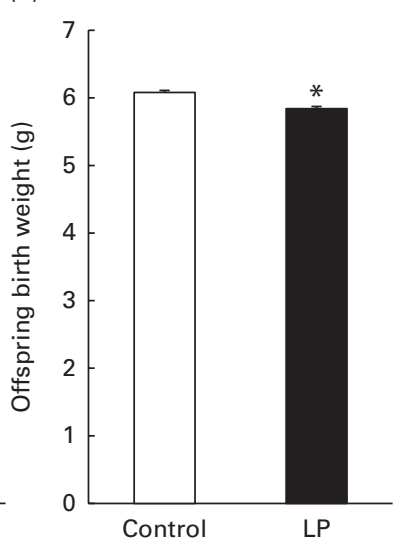

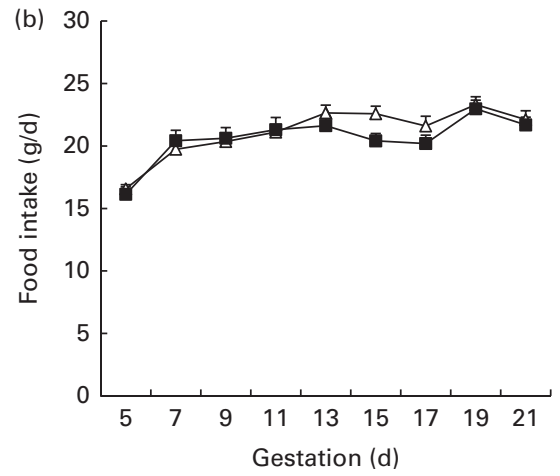

(e)

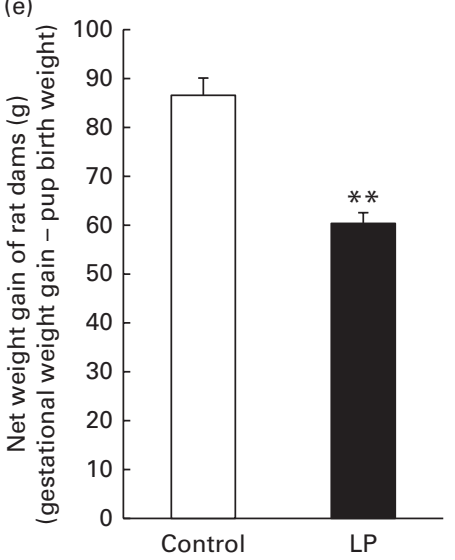

Fig. 1. Body weight (a), food intake (b), gestational weight gain (c), offspring birth weight (d) and gestational net weight gain (e) of rat dams consuming a control $(-\Delta-)$ or low-protein $(\mathrm{LP},-\mathbf{-}-)$ diet throughout gestation in study 1. Values are means $(n 6)$, with their standard errors represented by vertical bars. Where not visible, the error bars are too small to be seen. Mean value was significantly different from that of the control group: ${ }^{\star} P<0.05,{ }^{\star *} P<0.01$. 
defined as those predicted in EIDorado and elongated at the $3^{\prime}$ end of the promoter (downstream) by $150 \mathrm{bp}$. Position weight and matrices were used according to the Matrix Family Library version 8.2 (Genomatix, January 2010) for promoter analysis (Fig. 4(a)).

\section{Statistical analysis}

Data are presented as means and standard deviations. Food intake and body weight were analysed by repeatedmeasures one-way ANOVA (SAS Institute, Inc.). Two-way ANOVA was used for chromatin immunoprecipitation data with a Tukey post hoc comparison. Student's $t$ test was used for two-group comparisons (control $v$. LP), including plasma amino acid concentrations, mRNA expression and protein expression. Differences were considered significant at $P<0.05$ and $P<0.01$. Sample size was calculated by statistical power analysis based on 95\% CI using Statistical Solutions, LLC.

\section{Results}

\section{Gestational low-protein diet reduces weight gain} in rat dams

Pregnant rats consuming a LP diet weighed significantly less than the control group at days 17, 19 and 21 of gestation $(P<0.01$; Fig. 1(a)), but food intake was not significantly different in LP rat dams compared with the control group (Fig. 1(b)). Gestational weight gain was significantly lower in the LP group than in the control group $(P<0.01$, Fig. 1(c)). Litter sizes were not different between the control and LP groups. The birth weight of LP offspring was significantly lower $(P<0 \cdot 05$, Fig. $1(\mathrm{~d}))$ than that of the control group. However, even after taking offspring birth weight into consideration, net gestational weight gain (after subtracting pup birth weight) remained significantly lower in LP dams when compared with the control group $(P<0 \cdot 01$, Fig. 1(e)).

\section{Gestational low-protein diet alters the plasma amino acid profile in rat dams}

At the end of pregnancy, circulating Thr and His levels were significantly lower $(P<0.05)$ in LP dams than in the control group (Table 2). Lys, Ala and Ser were significantly higher $(P<0.05)$ in the LP group, while Leu, Ile, Lys, Met, Val, Glu, Asp, Pro, Tyr, Arg and Gly did not differ between the groups (see online Supplementary Table S3).

\section{Gestational low-protein diet induces skeletal muscle atrophy in rat dams}

Muscle consists of bundles of multinucleated cells, called muscle fibres or myofibres, which were assessed in rat dams after delivery using haematoxylin and eosin. A gestational LP diet has been reported to alter the mechanical properties of skeletal muscle in male offspring ${ }^{(34)}$; however, the consequences for the dam have not been reported. After delivery,
Table 2. Plasma amino acid profile of rat dams in study 1

(Mean values with their standard errors; $n 6$ )

\begin{tabular}{lccccr}
\hline & \multicolumn{2}{c}{$\begin{array}{c}\text { Control }(20 \% \text { of } \\
\text { energy) }\end{array}$} & & \multicolumn{2}{c}{ LP (8\% of energy) } \\
\cline { 2 - 3 } \cline { 5 - 6 } Amino acids $(\mu \mathrm{mol} / \mathrm{l})$ & Mean & SEM & & Mean & SEM \\
\cline { 2 - 3 } Ala & 692 & 22 & & $1020^{*}$ & 61 \\
Lys & 1440 & 49 & & $1830^{*}$ & 55 \\
Ser & 741 & 32 & & $1140^{*}$ & 135 \\
His & 961 & 56 & & $598^{*} \dagger$ & 61 \\
Thr & 973 & 60 & & $604^{*} \dagger$ & 85 \\
\hline
\end{tabular}

${ }^{*}$ Mean value was significantly different from that of the control group $(P<0.05)$ $\dagger$ Indicates decreased values.

we observed more varied sizes of muscle fibres, splitting muscle fibres and clustered basophilic fibres in the skeletal muscle of the LP group when compared with the control group (Fig. 2(a)). Fibres in the size range of $46-65 \mu \mathrm{m}$ were decreased in the LP group when compared with the control group $(P<0.05)$, whereas the LP group had more fibres in the size range of $66-91 \mu \mathrm{m}$ when than the control group (Fig. 2(b)). Overall, the gestational LP diet caused a more varied distribution of fibre diameters than the control diet (Fig. 2(c)) in the skeletal muscle of dams. Furthermore, the gestational LP diet significantly decreased the overall average skeletal muscle fibre size in rat dams (Fig. 2(d)), which has previously been associated with myopathy ${ }^{(22,23,35)}$.

Gestational low-protein diet induces amino acid response pathway-related target genes in the skeletal muscle of rat dams

The impact of gestational protein restriction on the AAR pathway was assessed by investigating the mRNA expression of AAR downstream genes (Asns, Atf3 and Chop) in the visceral adipose tissue, gastrocnemius (skeletal) muscle, liver and blood of rat dams after delivery. The gestational LP diet induced the mRNA expression of Asns (2-fold, $P<0.05$ ), Atf3 (1-fold, $P<0.05)$ and Chop (1.5-fold, $P<0.05)$ when compared with the control diet in skeletal muscle (Fig. 3(a)) but not in other tissues (liver Atf3 expression: $P=0.08$ for the LP diet; Fig. 3(b)). These results show that the gestational LP diet induces a tissue-specific response of AAR downstream genes in rat dams.

\section{Gestational low-protein diet increases activating} transcription factor 4 protein expression and phosphorylation of eukaryotic translation initiation factor $2 \alpha$ as well as activating transcription factor 4 binding at the promoter regions of amino acid response genes in the skeletal muscle of rat dams

To confirm the activation of the AAR pathway, the protein abundance of whole-cell p-eIF $2 \alpha$ and ATF 4 was analysed in the skeletal muscle of dams after delivery (Fig. 4(a) and (b)). Phosphorylation of eIF2 $\alpha$ on Ser 51, an upstream event required for the activation of the AAR pathway, was higher 
(a)

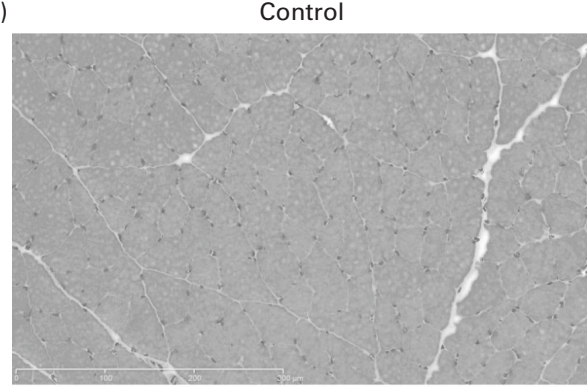

LP

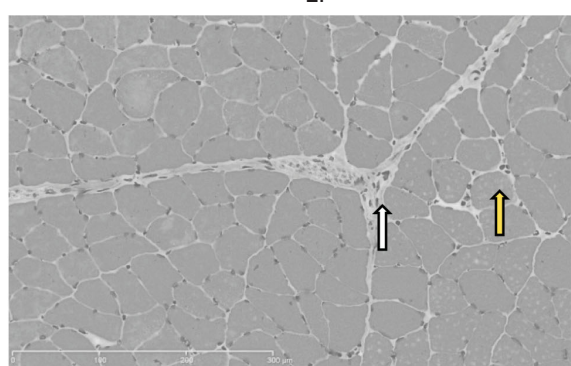

(b)

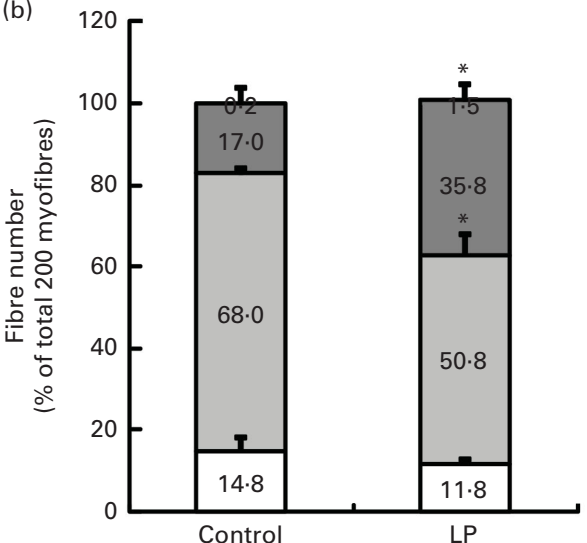

(c)

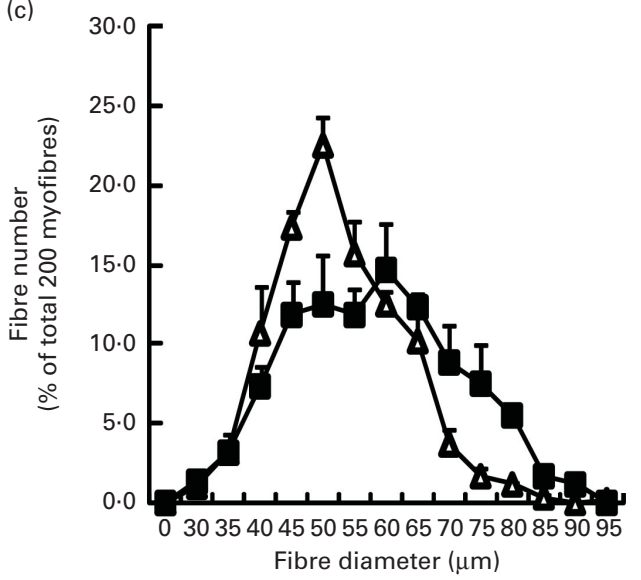

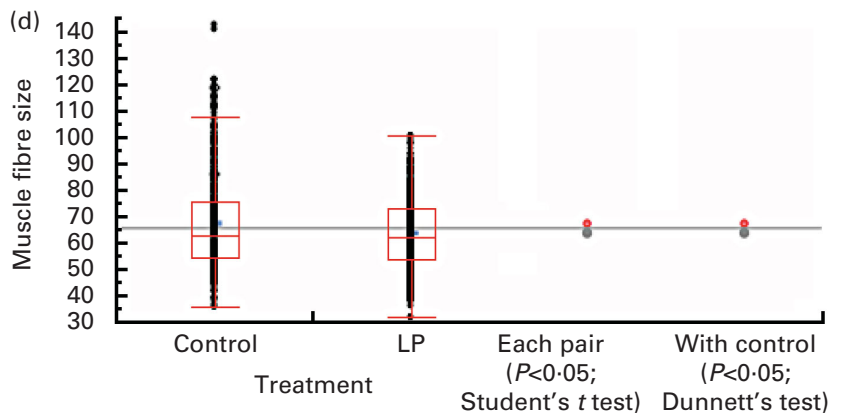

Fig. 2. Haematoxylin and eosin (H\&E) staining (a), quantification (b, d) and distribution analysis (c) of the skeletal muscle fibres of rat dams consuming a control or low-protein (LP) diet throughout gestation in study 1. H\&E staining was used to investigate the structural changes in the skeletal muscle of rat dams after a gestational LP diet. Two representative images were chosen to show the structural differences in skeletal muscle between the control and LP groups at a magnification of $20 \times$. $\Uparrow$, Clustered basophilic fibres; $\Uparrow$, varied sizes of muscle fibres and splitting muscle fibres. For quantification of muscle fibre percentage by different diameter ranges, each bar comprises the percentage distribution of fibre number in four different ranges of muscle fibre diameters, including $0-45$ ( $\square$ ), $46-65$ ( $\square$ ), 66-91 $(\square)$ and 92-140 $\mu \mathrm{m}(\square)$. The $X$-axis represents the treatment group, while the $Y$-axis shows the percentage of fibre number in each diameter range. Values are means $(n 6)$, with their standard errors represented by vertical bars. * Mean value was significantly different from that of the control group $(P<0 \cdot 05)$. (c) $-\Delta-$, Control group; - $\square-$, LP group. The $X$-axis shows a series of fibre diameters and the $Y$-axis shows the percentage of fibre number. (d) ......, Control group; $\bullet$ LP group. (A colour version of this figure can be found online at http://www.journals.cambridge.org/bjn).

in the skeletal muscle of the LP group compared with the control group (Fig. 4(a) and (b)), and muscle ATF4 protein expression was significantly higher in the LP group than in the control group (Fig. 4(a) and (b)). Based on the observed increased mRNA expression of ATF4 target genes, we investigated the binding of ATF 4 at the promoter regions of these genes in the skeletal muscle of dams after delivery. Overall, ATF 4 binding was significantly induced by the gestational LP diet at the predicted regions of the genes examined, including Asns (3-fold, $P<0.05$ ), Atf3 (1.5-fold, $P=0.06$ ) and Chop (4.5fold, $P<0.05$ ) (Fig. $4(\mathrm{c})$ ), thus confirming the ATF4-induced activation of the AAR pathway in the muscle of rat dams at the end of gestation.

\section{Gestational low-protein diet increases the mRNA expression of autophagy pathway-related genes and LC3B protein expression in the skeletal muscle of rat dams}

The proposed process of cellular autophagy and its relationship with the AAR pathway is described in Fig. 5(a) (adapted from the literature $\left.{ }^{(21,24,36)}\right)$. The mRNA expression of autophagy-related genes, including LC3a (1.5-fold, $P<0 \cdot 05$,), 


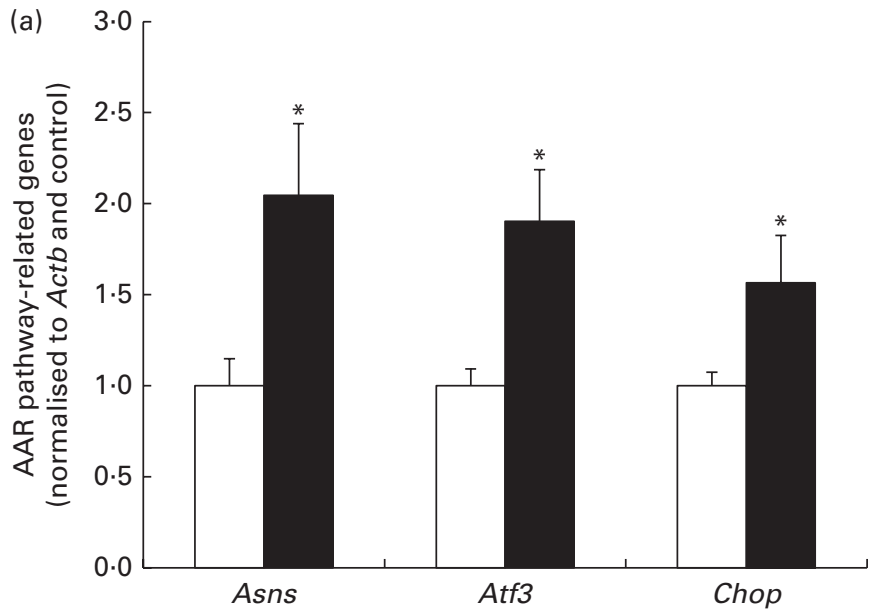

(b)

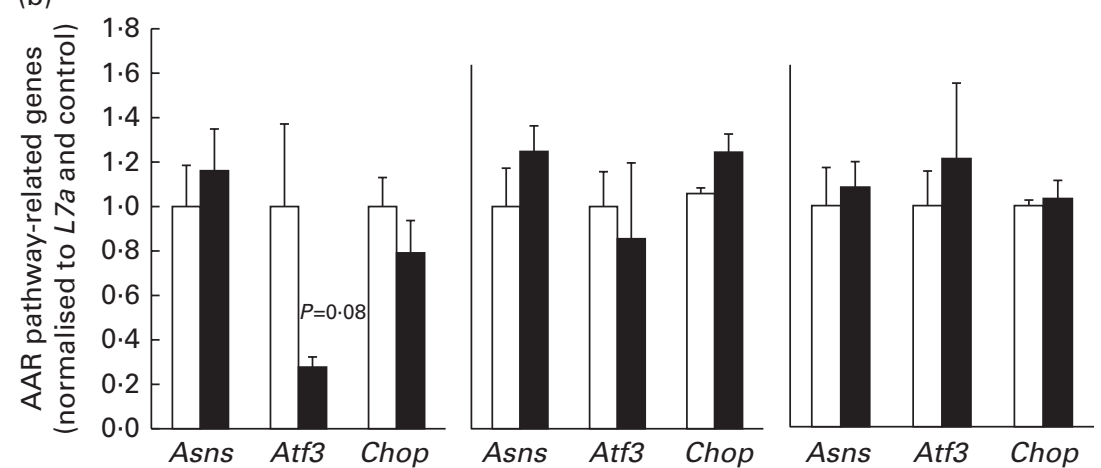

Fig. 3. mRNA expression of Asns (asparagine synthetase), Atf3 (activating transcription factor 3 ) and Chop (C/EBP homology protein) in the muscle (a), liver (b), adipose (b) and blood (b) of rat dams consuming a control $(\square)$ or low-protein (LP, $\square$ ) diet throughout gestation in study 1 . To detect the activation of the amino acid response (AAR) pathway, mRNA expression was analysed by two-step real-time RT-PCR in skeletal muscle. All data were normalised to the expression level of the housekeeping gene $\beta$-actin (Actb) (muscle) or 60S ribosomal protein (L7a) (liver, adipose and blood), and data from the LP group were further normalised to that of the control group. Values are means $(n 6)$, with their standard errors represented by vertical bars. Mean value was significantly different from that of the control group: * $P<0.05$.

LC3b (2-fold, $P<0.05)$, Bnip3 (2.5-fold, $P<0.05$ ) and Atg $4 b$ (1.4-fold, $P<0.05)$, was significantly induced in dams fed the gestational LP diet (Fig. 5(b)). Furthermore, to confirm the observed activation of autophagy, the protein abundance of whole-cell LC3B was analysed in the skeletal muscle of dams. The protein expression of LC3B, which was used as the primary indicator of autophagy, was higher in the skeletal muscle of LP dams when compared with the control group (2-fold, $P<0 \cdot 05$; Fig. 5(c)).

\section{Gestational low-protein diet induces activating} transcription factor 4 binding at the regions of autophagy pathway-related genes predicted by bioinformatics analysis in the skeletal muscle of rat dams

Based on the increased mRNA expression of autophagyrelated genes and the proposed relationship between autophagy and AAR, we investigated ATF 4 binding at the predicted regions of downstream autophagy pathway-related genes in the skeletal muscle of dams (Fig. 6(a)). When compared with the control, the gestational LP diet in dams increased ATF4 binding at the predicted regions of the autophagy-related genes examined, including $L C 3 a$ (2-fold, $P<0 \cdot 01$ ), LC3b (2-fold, $P<0 \cdot 05$ ), Atg4b (2.5-fold, $P<0.01$ ) and Bnip3 (1.5-fold, $P<0.05$ ) (Fig. 6(b)).

Gestational low-protein diet induces amino acid response pathway- and autophagy pathway-related genes in the skeletal muscle of male offspring

Our previous study showed that the placenta may sense gestational protein limitation, which is associated with growth restriction in the offspring ${ }^{(25)}$. To investigate whether these previous observations and the observation of the present study that maternal skeletal muscle is potentially involved in response to gestational protein limitation, we investigated the mRNA expression of both AAR- and autophagy-related genes in the skeletal muscle of offspring in our previously described study. Similar to what was observed in dams at delivery, the gestational LP diet significantly induced the mRNA expression of Asns (2-fold, P<0.01), Atf3 (5-fold, $P<0.05$ ) and Chop (2-fold, $P<0.01$ ) in male, but not in female, offspring skeletal muscle (Fig. 7(a)). Furthermore, and also similar to that observed in the dam, the mRNA 
(a)
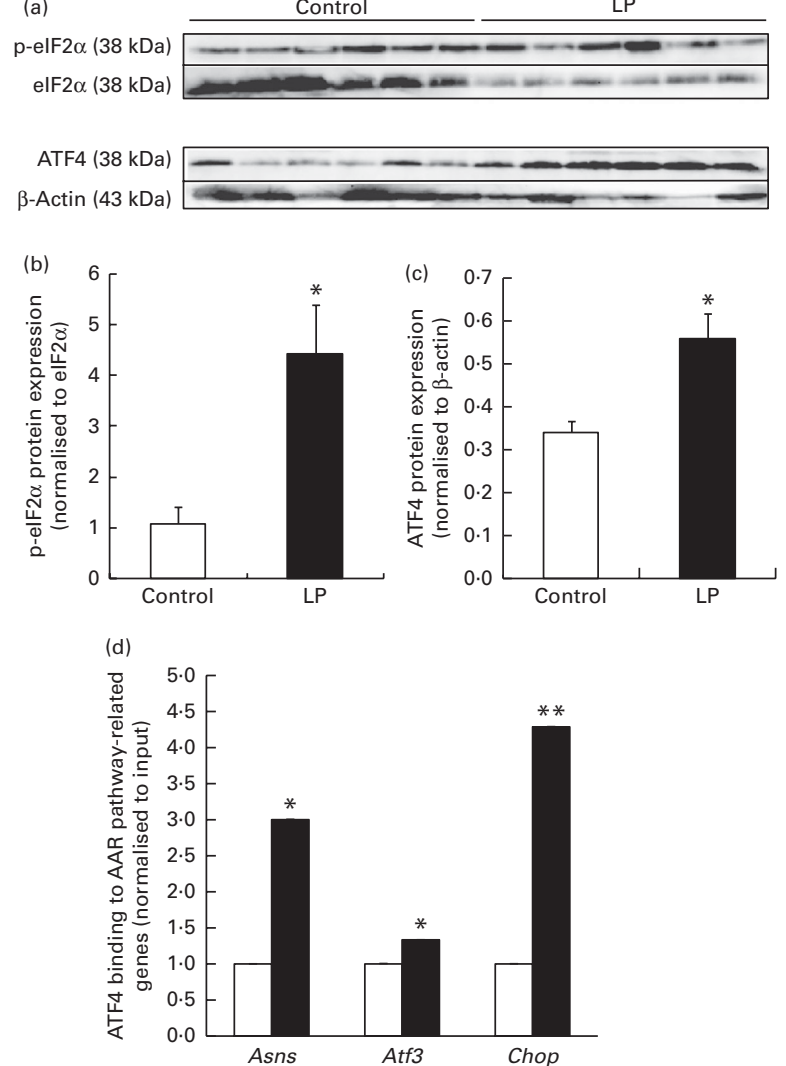

Fig. 4. Protein expression of phosphorylated eukaryotic translation initiation factor $2 \alpha$ (p-elF2 $\alpha)(a, b)$, activating transcription factor 4 (ATF4) (c, d), and ATF4 binding at the promoter regions of Asns (asparagine synthetase), Atf3 (activating transcription factor 3 ) and Chop (C/EBP homology protein) (d) in rat dams consuming a control $(\square)$ or low-protein $(L P, \square)$ diet throughout gestation in study 1 . Total elF2 $\alpha$ was used to normalise the phosphorylation of elF2 $\alpha$, and $\beta$-actin was used to normalise the protein expression of ATF4. The immunoblots shown are representative of the total sample size. Values are means $(n 6)$, with their standard errors represented by vertical bars. Mean value was significantly different from that of the control group: ${ }^{*} P<0.05,{ }^{*} P<0.01$. AAR, amino acid response.

expression of autophagy-related genes, including $L C 3 a$ (3-fold, $P<0.05$ ), LC3b (5-fold, $P<0.01$ ), Atg2a (2-fold, $P<0.05$ ) and Atg $4 b$ (4-fold, $P<0.05$ ), was significantly induced by the gestational LP diet in male, but not in female, offspring skeletal muscle (Fig. 7(b)).

\section{Discussion}

To our knowledge, the present study is the first to demonstrate the following novel mechanisms: first, a gestational LP diet alters the maternal plasma amino acid profile, together with decreased maternal and pup body weights and apparent muscle dystrophy in the dam at delivery in an in vivo rat pregnancy model. Second, the LP diet produced tissue-specific activation of AAR and autophagy pathway-related genes only in maternal skeletal muscle, but not in the liver, blood or adipose tissue. Third, the LP diet increased ATF4 binding within specific autophagy-related target genes, confirming a molecular link between the activation of the AAR signal and the autophagy pathway. Together, these data, as well as the follow-up data showing that in the skeletal muscle of male offspring fed a gestation LP diet, AAR- and autophagy-related genes remain elevated, provide insight into the transduction of the gestational amino acid limitation signal from maternal muscle, to the placenta ${ }^{(25)}$, and to the offspring. A proposed schematic diagram highlights the mechanism that a gestational LP diet programmed offspring growth capacity through signal transduction from the skeletal muscle of the rat dam (Fig. 8). Furthermore, the molecular mechanisms described in the present study offer novel insight into the role of ATF 4 in activating critical autophagy-related genes in the skeletal muscle of pregnant dams, providing specific molecular changes that could be memorised in the offspring long after gestational protein restriction.

The present study demonstrates that consumption of a LP diet throughout pregnancy altered multiple physiological outcomes in rat dams. Gestational weight gain was decreased in LP dams (after accounting for cumulative offspring birth weight), as were the birth weight of the LP offspring. It has been reported that exposure of the pregnant rat to a LP diet ( $8 \%$ of energy from protein) causes a decrease in maternal body weight without a significant difference in food intake $^{(37)}$, which is consistent with the findings from the present study. Fasting blood glucose levels of LP rat dams $(3.53 \mathrm{mmol} / \mathrm{l})$ tended to be lower $(P=0.06)$ than the control group $(6.28 \mathrm{mmol} / \mathrm{l}$; data not shown $)$, which is in agreement with the findings of Wapnir \& Lifshitz ${ }^{(38)}$ showing that a LP diet can cause a decrease in fasted blood glucose concentration in rats. Furthermore, muscle fibre perimeter was overall significantly different in LP dams when compared with the control group. Previous studies have demonstrated that decreased fibre size is linked to myopathy ${ }^{(35)}$, and our findings suggest that gestationally protein-restricted dams adapt to the growing protein needs of pregnancy through the breakdown of maternal muscle.

We observed that a gestational LP diet was associated with significant decreases in maternal plasma Thr concentration, consistent with the findings from a previous study showing that protein limitation decreases circulating Thr concentration in pregnant rats ${ }^{(39)}$. There were also changes in Lys, Ala and Ser concentrations in the LP group, consistent with other studies reporting increased mobilisation of maternal protein stores during dietary restriction ${ }^{(40)}$. The increased plasma concentration of the essential amino acid Lys cannot be explained by de novo synthesis, and can only result from increased protein breakdown or reduced hepatic catabolism. The breakdown of maternal protein stores by a gestational LP diet is further confirmed by the observed increase in Ala concentration, which has a central role in gluconeogenesis and serves to remove $\mathrm{N}$ and recycle glucose carbon as part of the 'alanine cycle' associated with branched-chain amino acid oxidation in skeletal muscle ${ }^{(41)}$. Increased Ala and Lys concentrations have also been previously observed in a pregnant pig model of protein restriction ${ }^{(41)}$.

At the end of gestation, the LP diet induced the activation of AAR and autophagy pathways in maternal skeletal muscle. The mechanism of AAR pathway activation in response to amino acid deprivation has been well documented in 

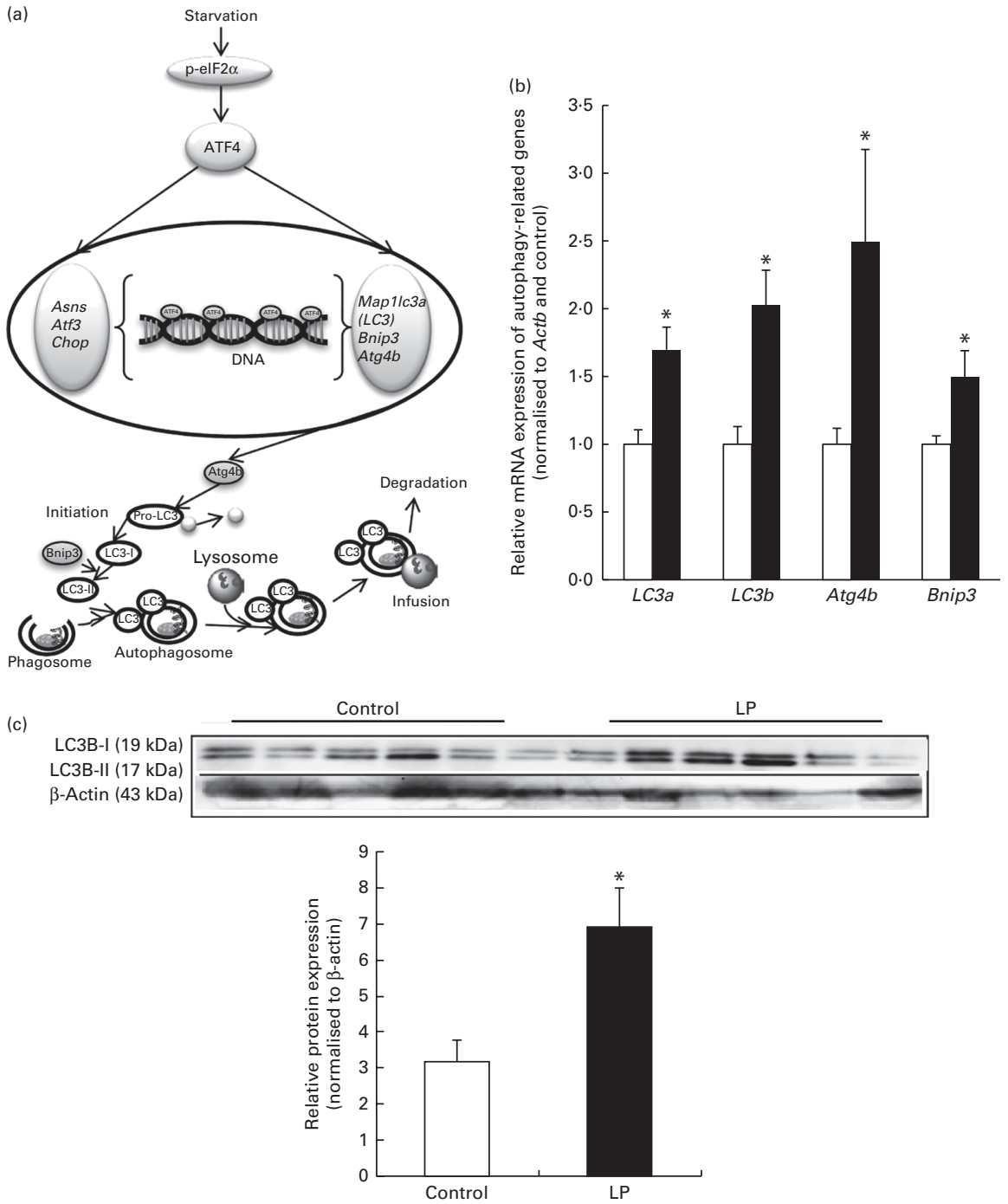

Fig. 5. Schematic diagram of cellular autophagy (a), autophagy gene expression (b) and LC3B protein expression (c) in the skeletal muscle of rat dams consuming a control $(\square)$ or low-protein (LP, $\square$ ) diet throughout gestation in study 1 . To detect the activation of the autophagy pathway, mRNA expression was analysed by two-step real-time RT-PCR in skeletal muscle. All data were normalised to the expression level of the housekeeping gene $\beta$-actin (Actb), and data from the LP group were further normalised to that of the control group. $\beta$-Actin was used to normalise the protein expression of LC3B. The immunoblots shown are representative of the total sample size. Values are means $(n 6)$, with their standard errors represented by vertical bars. Mean value was significantly different from that of the control group: ${ }^{*} P<0.05$. p-elF2 $\alpha$, phophorylated eukaryotic translation initiation factor $2 \alpha$; ATF4, activating transcription factor 4 ; Asns, asparagine synthetase; Chop, C/EBP homology protein; LC3a, microtubule-associated protein 1 light chain $3 \alpha$; LC $3 b$, microtubule-associated protein 1 light chain $3 \beta$; Bnip3, BCL2/adenovirus E1B-interacting protein 3; Atg4b, cysteine protease ATG4b.

in vitro studies ${ }^{(7,42)}$, but remains poorly characterised in animals. Decreased Thr concentration has been previously shown to activate the AAR pathway in HepG2 cells ${ }^{(43)}$. In another study, a Thr-deficient diet has been found to activate the AAR pathway in an animal model ${ }^{(44,45)}$. The present study demonstrates that decreases in plasma Thr and His concentrations are primary indicators of protein limitation in maternal plasma after gestation, consistent with in vitro data for the activation of the AAR pathway ${ }^{(43)}$. Our results show that a robust activation of the AAR pathway occurred only in skeletal muscle following a gestational LP diet, which was illustrated by the increased mRNA expression of the AAR-responsive genes and ATF 4 and $\mathrm{p}$-eIF $2 \alpha$ protein expression. Previous research has shown that increased ATF4 expression promoted skeletal myofibre atrophy during fasting ${ }^{(23)}$. Moreover, Naismith \& Morgan ${ }^{(46)}$ found that protein redistribution occurs during pregnancy, and it has also been shown that muscle has the greatest role during this period of active protein metabolism $^{(46-48)}$. While amino acid availability is associated with the regulation of autophagy in yeast and mammalian cells $^{(49)}$, in vivo data are scarce. In the present study, we showed that the LP diet induced the activation of the autophagy pathway in the skeletal muscle of rat dams. Macroautophagy is highly associated with cellular metabolism, and autophagy in skeletal muscle has both beneficial and detrimental roles, depending on the stage of protein metabolism $^{(50)}$. It has been reported that starvation can induce autophagy in the muscle of mice ${ }^{(51)}$. Furthermore, It has 
(a)

Consensus ATF4 binding site:

[TC]GA[CT]G[TCG][AC][AT]

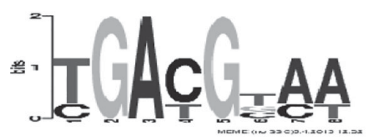

\begin{tabular}{|c|c|c|c|c|c|c|}
\hline Name & Strand & Start & $P$-value & Sites & & \\
\hline Atg $4 b$ & + & 7 & $5.03 \times 10^{-5}$ & TAGAAA & T:ATGTAA & OCTGGGT \\
\hline Bnip3 & - & 10 & $9.11 \times 10^{-5}$ & GTTC & T:AC:TCA & CGCTGGGAG \\
\hline$\angle C 3 A$ & + & 1 & $1.53 \times 10^{-4}$ & & T:AC & AYOCOCOGGG \\
\hline$\angle C 3 A$ & - & 21 & $2.49 \times 10^{-4}$ & c & CऽACSCAA & AACCCGGGGG \\
\hline
\end{tabular}

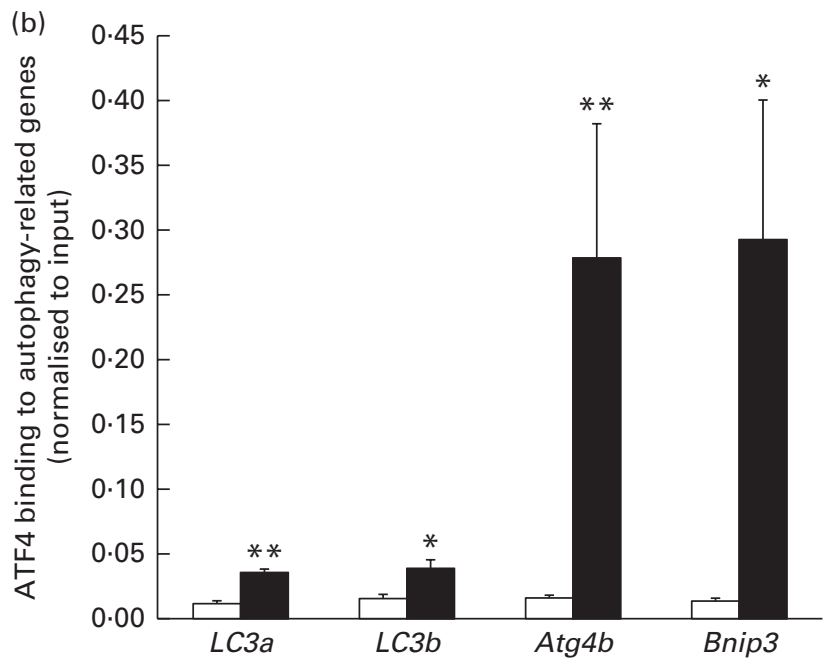

Fig. 6. Binding of activating transcription factor 4 (ATF4) to autophagyrelated genes $(a, b)$ in rat dams consuming a control $(\square)$ or low-protein (LP, $\mathbf{\square})$ diet throughout gestation in study 1 . The binding sites of the ATF4 transcription factor at the promoter regions of $L C 3 a$ (microtubule-associated protein 1 light chain $3 \alpha$ ), LC3b (microtubule-associated protein 1 light chain $3 \beta$ ), Atg $4 b$ (cysteine protease ATG4b) and Bnip3 (BCL2/adenovirus E1B-interacting protein 3 ) were predicted by Genomatix software. Values are means $(n 6)$, with their standard errors represented by vertical bars. Mean value was significantly different from that of the control group: ${ }^{\star} P<0.05$, ${ }^{\star \star} P<0.01$.

been shown that eIF $2 \alpha /$ ATF 4 plays an important role in activating stress-induced autophagy gene expression in vitro ${ }^{(24)}$, and data from the present study demonstrate that autophagy is also activated in the skeletal muscle of pregnant rats consuming a protein-deficient diet.

In support of the ATF4-induced gene expression in muscle, the binding of the ATF 4 transcription factor was consistently increased at the promoter regions of both AAR and autophagy pathway-related genes in response to the LP diet. We observed the binding of ATF 4 at the promoter regions of Asns, Atf3 and Chop, which was associated with the induction of mRNA expression similar to the ATF4-mediated activation of the AAR pathway in vitro in hepatoma cells ${ }^{(7)}$. Increased ATF 4 binding also occurred the promoter regions of $L C 3 a, L C 3 b$, Atg $4 b$ and Bnip3 along with increased mRNA expression of these autophagy pathway-related genes. ATF4 is known to regulate the hypoxia-inducible factor-1 (HIF-1) target gene carbonic anhydrase 9. Here, we show that another HIF-1 target gene, Bnip3 ${ }^{(52,53)}$, can also be regulated by ATF4. Furthermore, we observed increased LC3B protein expression, which has been used as a biomarker for the activation of autophagy in muscle ${ }^{(54)}$. These data demonstrate that in addition to the role of ATF 4 in the activation of the AAR pathway in response to protein restriction, this transcription factor also activates autophagy pathway-related genes in the muscle of protein-deficient pregnant dams. Furthermore, while gestational protein restriction has previously been shown to affect the skeletal muscle of offspring ${ }^{(55,56)}$, we further demonstrate that both AAR and autophagy pathways remain activated in male offspring long after the exposure to a gestational LP diet, suggesting that the induction of autophagy through the activation of the ATF4-dependent AAR pathway in the mother may act as the molecular memory of the forthcoming expected environment in the offspring. A LP diet during pregnancy could be memorised in the offspring in different ways. From physiological point of view, during pregnancy, the fetus obtains amino acid resource through the umbilical cord from
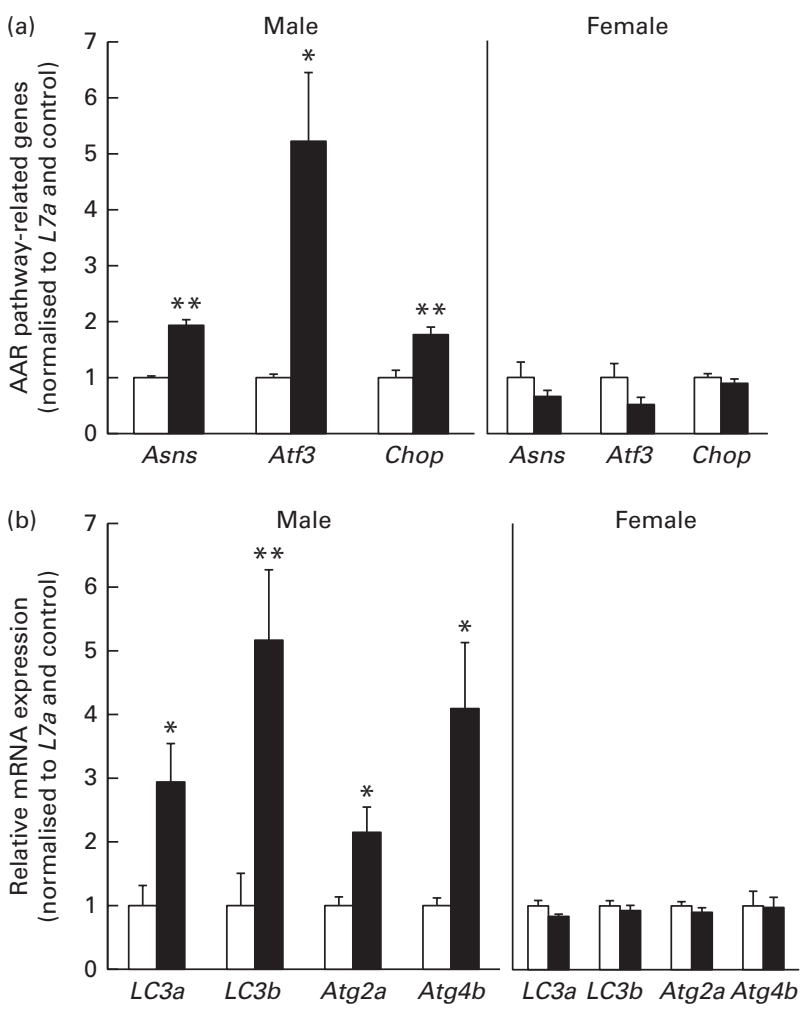

Fig. 7. mRNA expression of amino acid response (AAR) pathway-related genes (a) and autophagy pathway-related genes (b) in the skeletal muscle of offspring whose dams consumed a control ( $\square$ ) or low-protein (LP, $\square$ ) diet throughout gestation in study 2. To detect the activation of the AAR pathway and autophagy in the offspring, mRNA expression was analysed by two-step real-time RT-PCR in skeletal muscle. All data were normalised to the expression level of the housekeeping gene $60 \mathrm{~S}$ ribosomal protein $(L 7 a)$, and data from the maternal LP group were further normalised to that of the control group. Values are means $(n 6)$, with their standard errors represented by vertical bars. Mean value was significantly different from that of the control group: ${ }^{\star} P<0.05,{ }^{\star *} P<0.01$. Asns, asparagine synthetase; Atf3, activating transcription factor 3; Chop, C/EBP homology protein; Atg2a, cysteine protease ATG2a; Atg4b, cysteine protease ATG4b. 

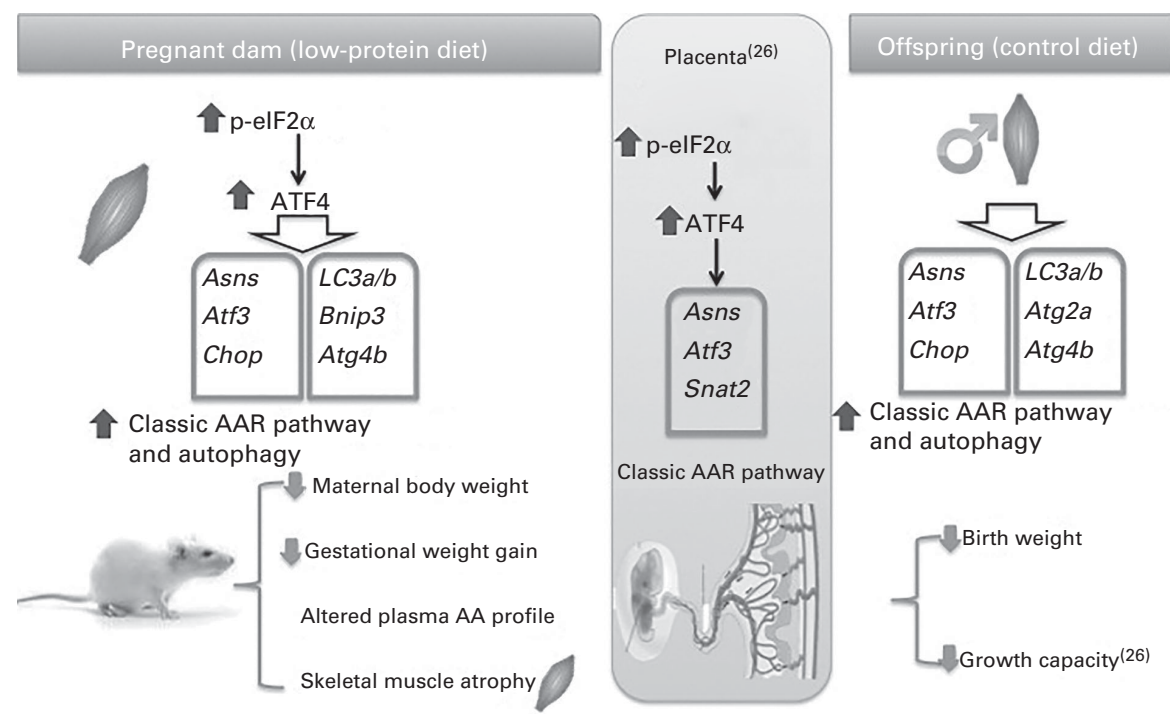

Fig. 8. Diagram of the proposed maternal programming mechanism by a gestational low-protein diet in rat dams. The results highlight that a gestational lowprotein diet activates the amino acid response (AAR) pathway and potentially initiates autophagy in the skeletal muscle of the rat dam. The signal is potentially transduced to the placenta and further to the skeletal muscle of male offspring, which may potentially link to the stunted growth in the offspring. Asns, asparagine synthetase; Atf3, activating transcription factor 3; Snat2, sodium-coupled neutral amino acid transporter 2; Chop, C/EBP homology protein; LC3a/b, microtubuleassociated protein 1A/1B light chain 3 $\alpha / \beta$; Bnip3, BCL2/adenovirus E1B-interacting protein 3; Atg4b, cysteine protease ATG4b; AA, amino acids.

the placenta. Therefore, an altered amino acid profile in mother has a direct influence on the amino acid profile in the fetus. It has been shown that amino acid profile was altered in the fetus on pregnancy day 19 by maternal LP diet $^{(39)}$. From molecular point of view, altered amino acid supply triggers subsequential signalling pathways in embryonic development. A LP diet during pregnancy can programme blastocyst development, which is potentially due to the activation of the mammalian target of rapamycin (mTOR) signalling pathway triggered by altered maternal serum amino acids in mice ${ }^{(57)}$. Moreover, epigenetics may be the key to explain the 'memory'. The maternal programming model has been well established in a gestational LP diet to investigate epigenetic regulation including histone modification and DNA methylation. The effect of epigenetics is tissue- and sex-dependent. Histone acetylation of glucose transporter type 4 (Glut4) was induced by a gestational LP diet in the skeletal muscle of female offspring ${ }^{(58)}$, and the diet decreased histone $\mathrm{H} 3$ acetylation and methylation of cyclin-dependent kinase inhibitor $1 \mathrm{~A}(p 21)$ in the mammary gland of the offspring ${ }^{(59)}$. Also, increased hepatic DNA methylation of insulin-like growth factor 2 (Igf2) could be caused by a LP diet during pregnancy ${ }^{(60)}$. It appears that the effects of the maternal LP diet may be memorised in the offspring through multiple epigenetic mechanisms.

Sex dimorphism of fetal programming has been studied intensively over the years. It potentially originates from the placenta through sex-specific epigenetic regulations ${ }^{(61)}$. Therefore, male and female respond differently to maternal protein restriction depending on the type of metabolic pathways and tissues. A LP diet during gestation can induce Glut4 expression in the skeletal muscle of female offspring ${ }^{(58)}$, but no effect in male offspring. However, AAR and autophagy pathway-related genes are only up-regulated in the skeletal muscle of male offspring, possibly involve hormonal regulation. The development of male skeletal muscle is related to male hormones ${ }^{(62)}$. Moreover, it has been shown that a protein restriction diet during pregnancy and lactation impairs male testosterone levels ${ }^{(63)}$. This may explain the differentiated transcriptional regulation of AAR and autophagy pathways in the skeletal muscle of male and female offspring.

The present study demonstrates that maternal protein restriction results in decreased Thr and His concentrations in plasma together with the activation of the ATF4-dependent AAR pathway, which may initiate autophagy in the skeletal muscle of rat dams. We showed that the transcriptional activation of target genes was associated with the binding of the ATF 4 transcription factor at the promoter regions of these genes in AAR and autophagy pathways. Furthermore, a follow-up analysis of gestational protein restriction in the offspring confirmed that both pathways remained activated in the skeletal muscle of the offspring long after birth. Imbalanced and inadequate protein intake in women during pregnancy is an epidemic problem in developing countries ${ }^{(64,65)}$. Recently, a new cohort in Canada showed that the requirement for protein intake is actually higher than the current recommendations in healthy pregnant women during early and late gestation $^{(66)}$. However, few epidemiological studies have focused on the response to maternal protein restriction in the mother. Not only the offspring, but also the mother has detrimental effects in response to protein restriction, and the present study sheds light on maternal healthcare for both women and babies. Classifying these protein-sensing mechanisms in the mother may help to diagnose potential muscleassociated diseases in response to LP intake during pregnancy, as well as to further investigate the precise role of maternal signalling in the growth restriction observed in the offspring in response to maternal protein deficiency. 


\section{Supplementary material}

To view supplementary material for this article, please visit http://dx.doi.org/10.1017/S0007114515002172

\section{Acknowledgements}

The authors thank Dr Rita Strakovsky from the University of Illinois at Urbana-Champaign for copyediting and technical advice.

The present study was supported by funding from the UIUC Research Board (grant no. RB14148) and the Division of Nutritional Sciences (Vision 20/20 grant), and supported by the USDA Cooperative State Research, Education and Extension Service (project no. \#ILLU-698-374). The sponsors had no role in the design and analysis of the study or in the writing of this article.

The contributions of the authors are as follows: the experiments were performed in the laboratory of Y.-X. P. at the University of Illinois at Urbana-Champaign; Y.-X. P. and $\mathrm{H}$. W. were responsible for the conception and design of the experiments; H. W. and G. J. W. performed the analysis of amino acids by HPLC in the laboratory of D. K. L. at the University of Illinois at Urbana-Champaign; H. W. conducted all the experiments and collected the data; D. Z., S. L. and $\mathrm{X}$. C. provided technical advice and assistance on the histological results; H. W. analysed the data, performed the statistical analysis and drafted the manuscript; Y.-X. P. and H. W. had the primary responsibility for the final content. All authors read and approved the final manuscript.

None of the authors has any conflict of interest to declare.

\section{References}

1. Rieger D, Loskutoff NM \& Betteridge KJ (1992) Developmentally related changes in the uptake and metabolism of glucose, glutamine and pyruvate by cattle embryos produced in vitro. Reprod Fertil Dev 4, 547-557.

2. Kalhan SC (2000) Protein metabolism in pregnancy. Am J Clin Nutr 71, 1249S-1255S

3. Metzger BE, Unger RH \& Freinkel N (1977) Carbohydrate metabolism in pregnancy. XIV. Relationships between circulating glucagon, insulin, glucose and amino acids in response to a "mixed meal" in late pregnancy. Metabolism 26, 151-156.

4. Felig P, Kim YJ, Lynch V, et al. (1972) Amino acid metabolism during starvation in human pregnancy. J Clin Invest 51, 1195-1202.

5. Kalkhoff RK, Kandaraki E, Morrow PG, et al. (1988) Relationship between neonatal birth weight and maternal plasma amino acid profiles in lean and obese nondiabetic women and in type I diabetic pregnant women. Metabolism 37, $234-239$

6. Snoeck A, Remacle C, Reusens B, et al. (1990) Effect of a low protein diet during pregnancy on the fetal rat endocrine pancreas. Biol Neonate 57, 107-118.

7. Kilberg MS, Shan J \& Su N (2009) ATF4-dependent transcription mediates signaling of amino acid limitation. Trends Endocrinol Metab 20, 436-443.

8. Barbosa-Tessmann IP, Chen C, Zhong C, et al. (2000) Activation of the human asparagine synthetase gene by the amino acid response and the endoplasmic reticulum stress response pathways occurs by common genomic elements. J Biol Chem 275, 26976-26985.

9. Pan Y, Chen H, Siu F, et al. (2003) Amino acid deprivation and endoplasmic reticulum stress induce expression of multiple activating transcription factor-3 mRNA species that, when overexpressed in HepG2 cells, modulate transcription by the human asparagine synthetase promoter. $J$ Biol Chem 278, 38402-38412.

10. Abcouwer SF, Schwarz C \& Meguid RA (1999) Glutamine deprivation induces the expression of GADD45 and GADD153 primarily by mRNA stabilization. J Biol Chem 274, 28645-28651.

11. Bruhat A, Jousse C, Wang XZ, et al. (1997) Amino acid limitation induces expression of $C H O P$, a CCAAT/enhancer binding protein-related gene, at both transcriptional and post-transcriptional levels. J Biol Chem 272, 17588-17593.

12. Lu PD, Harding HP \& Ron D (2004) Translation reinitiation at alternative open reading frames regulates gene expression in an integrated stress response. J Cell Biol 167, 27-33.

13. Harding HP, Novoa I, Zhang Y, et al. (2000) Regulated translation initiation controls stress-induced gene expression in mammalian cells. Mol Cell 6, 1099-1108.

14. Vattem KM \& Wek RC (2004) Reinitiation involving upstream ORFs regulates ATF4 mRNA translation in mammalian cells. Proc Natl Acad Sci U S A 101, 11269-11274.

15. Harding HP, Zhang Y, Zeng H, et al. (2003) An integrated stress response regulates amino acid metabolism and resistance to oxidative stress. Mol Cell 11, 619-633.

16. Chen H, Pan YX, Dudenhausen EE, et al. (2004) Amino acid deprivation induces the transcription rate of the human asparagine synthetase gene through a timed program of expression and promoter binding of nutrient-responsive basic region/leucine zipper transcription factors as well as localized histone acetylation. J Biol Chem 279, 50829-50839.

17. Pan YX, Chen H, Thiaville MM, et al. (2007) Activation of the ATF3 gene through a co-ordinated amino acid-sensing response programme that controls transcriptional regulation of responsive genes following amino acid limitation. Biochem J 401, 299-307.

18. Sandri M, Lin J, Handschin C, et al. (2006) PGC- $1 \alpha$ protects skeletal muscle from atrophy by suppressing FoxO3 action and atrophy-specific gene transcription. Proc Natl Acad Sci U S A 103, 16260-16265.

19. Nishino I (2003) Autophagic vacuolar myopathies. Curr Neurol Neurosci Rep 3, 64-69.

20. Mizushima N, Levine B, Cuervo AM, et al. (2008) Autophagy fights disease through cellular self-digestion. Nature $\mathbf{4 5 1}$, 1069-1075.

21. Mammucari C, Milan G, Romanello V, et al. (2007) FoxO3 controls autophagy in skeletal muscle in vivo. Cell Metab 6, 458-471.

22. Ebert SM, Dyle MC, Kunkel SD, et al. (2012) Stress-induced skeletal muscle Gadd45a expression reprograms myonuclei and causes muscle atrophy. J Biol Chem 287, 27290-27301.

23. Ebert SM, Monteys AM, Fox DK, et al. (2010) The transcription factor ATF4 promotes skeletal myofiber atrophy during fasting. Mol Endocrinol 24, 790-799.

24. B'Chir W, Maurin AC, Carraro V, et al. (2013) The eIF2alpha/ ATF4 pathway is essential for stress-induced autophagy gene expression. Nucleic Acids Res 41, 7683-7699.

25. Strakovsky RS, Zhou D \& Pan YX (2010) A low-protein diet during gestation in rats activates the placental mammalian amino acid response pathway and programs the growth capacity of offspring. J Nutr 140, 2116-2120. 
26. Reeves PG, Nielsen FH, Fahey GC, et al. (1993) AIN-93 purified diets for laboratory rodents: final report of the American Institute of Nutrition ad hoc writing committee on the reformulation of the AIN-76A rodent diet. J Nutr 123, 1939-1951.

27. Zheng S \& Pan YX (2011) Histone modifications, not DNA methylation, cause transcriptional repression of p16 (CDKN2A) in the mammary glands of offspring of proteinrestricted rats. J Nutr Biochem 22, 567-573.

28. Bayne K (1996) Revised guide for the care and use of laboratory animals available. American Physiological Society. Physiologist 39, 208-211.

29. Reverter M, Lundh T \& Lindberg JE (1997) Determination of free amino acids in pig plasma by precolumn derivatization with 6- $N$-aminoquinolyl- $N$-hydroxysuccinimidyl carbamate and high-performance liquid chromatography. J Chromatogr B Biomed Sci Appl 696, 1-8.

30. Zhang X, Zhou D, Strakovsky R, et al. (2012) Hepatic cellular senescence pathway genes are induced through histone modifications in a diet-induced obese rat model. $A m J$ Physiol Gastrointest Liver Physiol 302, G558-G564.

31. Kintscher U, Hartge M, Hess K, et al. (2008) T-lymphocyte infiltration in visceral adipose tissue: a primary event in adipose tissue inflammation and the development of obesity-mediated insulin resistance. Arterioscler Thromb Vasc Biol 28, 1304-1310.

32. Heinemeyer T, Wingender E, Reuter I, et al. (1998) Databases on transcriptional regulation: TRANSFAC, TRRD and COMPEL. Nucleic Acids Res 26, 362-367.

33. Cartharius K, Frech K, Grote K, et al. (2005) MatInspector and beyond: promoter analysis based on transcription factor binding sites. Bioinformatics 21, 2933-2942.

34. Toscano AE, Manhaes-de-Castro R \& Canon F (2008) Effect of a low-protein diet during pregnancy on skeletal muscle mechanical properties of offspring rats. Nutrition $\mathbf{2 4}$, 270-278.

35. Fox DK, Ebert SM, Bongers KS, et al. (2014) p53 and ATF4 mediate distinct and additive pathways to skeletal muscle atrophy during limb immobilization. Am J Physiol Endocrinol Metab 307, E245-E261.

36. Masiero E, Agatea L, Mammucari C, et al. (2009) Autophagy is required to maintain muscle mass. Cell Metab 10, 507-515.

37. Chamson-Reig A, Thyssen SM, Hill DJ, et al. (2009) Exposure of the pregnant rat to low protein diet causes impaired glucose homeostasis in the young adult offspring by different mechanisms in males and females. Exp Biol Med (Maywood) 234, 1425-1436.

38. Wapnir RA \& Lifshitz F (1977) Fasting-induced hypoglycemia in experimentally malnourished rats. J Nutr 107, 383-390.

39. Rees WD, Hay SM, Buchan V, et al. (1999) The effects of maternal protein restriction on the growth of the rat fetus and its amino acid supply. Br J Nutr 81, 243-250.

40. Wu G, Pond WG, Ott T, et al. (1998) Maternal dietary protein deficiency decreases amino acid concentrations in fetal plasma and allantoic fluid of pigs. J Nutr 128, 894-902.

41. Felig P (1973) The glucose-alanine cycle. Metabolism 22, 179-207.

42. Kilberg MS, Pan YX, Chen H, et al. (2005) Nutritional control of gene expression: how mammalian cells respond to amino acid limitation. Annu Rev Nutr 25, 59-85.

43. Palii S, Kays C, Deval C, et al. (2009) Specificity of amino acid regulated gene expression: analysis of genes subjected to either complete or single amino acid deprivation. Amino Acids 37, 79-88.

44. Hao S, Ross-Inta CM \& Gietzen DW (2010) The sensing of essential amino acid deficiency in the anterior piriform cortex, that requires the uncharged tRNA/GCN2 pathway, is sensitive to wortmannin but not rapamycin. Pharmacol Biochem Behav 94, 333-340.

45. Hao S, Sharp JW, Ross-Inta CM, et al. (2005) Uncharged tRNA and sensing of amino acid deficiency in mammalian piriform cortex. Science 307, 1776-1778.

46. Naismith DJ \& Morgan BL (1976) The biphasic nature of protein metabolism during pregnancy in the rat. $\mathrm{Br} \mathrm{J} \mathrm{Nutr}$ 36, 563-566.

47. Naismith DJ (1966) The requirement for protein, and the utilization of protein and calcium during pregnancy. Metabolism 15, 582-595.

48. Naismith DJ (1969) The foetus as a parasite. Proc Nutr Soc 28, 25-31.

49. Abeliovich H (2014) Regulation of autophagy by amino acid availability in $S$. cerevisiae and mammalian cells. Amino Acids (Epublication ahead of print version 29 June 2014)

50. Sandri M (2010) Autophagy in skeletal muscle. FEBS Lett 584, 1411-1416.

51. Mizushima N, Yamamoto A, Matsui M, et al. (2004) In vivo analysis of autophagy in response to nutrient starvation using transgenic mice expressing a fluorescent autophagosome marker. Mol Biol Cell 15, 1101-1111.

52. van den Beucken T, Koritzinsky M, Niessen H, et al. (2009) Hypoxia-induced expression of carbonic anhydrase 9 is dependent on the unfolded protein response. $\mathrm{J}$ Biol Chem 284, 24204-24212.

53. Guo K, Searfoss G, Krolikowski D, et al. (2001) Hypoxia induces the expression of the pro-apoptotic gene BNIP3. Cell Death Differ 8, 367-376.

54. Kazi AA \& Lang CH (2010) PRAS40 regulates protein synthesis and cell cycle in C2C12 myoblasts. Mol Med 16, 359-371.

55. Mortensen OH, Olsen HL, Frandsen L, et al. (2010) Gestational protein restriction in mice has pronounced effects on gene expression in newborn offspring's liver and skeletal muscle; protective effect of taurine. Pediatr Res 67, 47-53.

56. Zhu MJ, Ford SP, Nathanielsz PW, et al. (2004) Effect of maternal nutrient restriction in sheep on the development of fetal skeletal muscle. Biol Reprod 71, 1968-1973.

57. Eckert JJ, Porter R, Watkins AJ, et al. (2012) Metabolic induction and early responses of mouse blastocyst developmental programming following maternal low protein diet affecting life-long health. PLOS ONE 7, e52791.

58. Zheng S, Rollet M \& Pan YX (2012) Protein restriction during gestation alters histone modifications at the glucose transporter 4 (GLUT4) promoter region and induces GLUT4 expression in skeletal muscle of female rat offspring. J Nutr Biochem 23, 1064-1071.

59. Zheng S, Rollet M, Yang K, et al. (2012) A gestational lowprotein diet represses p21(WAF1/Cip1) expression in the mammary gland of offspring rats through promoter histone modifications. Br J Nutr 108, 998-1007.

60. Gong L, Pan YX \& Chen H (2010) Gestational low protein diet in the rat mediates $I g f 2$ gene expression in male offspring via altered hepatic DNA methylation. Epigenetics 5, 619-626

61. Gabory A, Roseboom TJ, Moore T, et al. (2013) Placental contribution to the origins of sexual dimorphism in health and diseases: sex chromosomes and epigenetics. Biol Sex Differ 4,5 .

62. Michel G \& Baulieu EE (1980) Androgen receptor in rat skeletal muscle: characterization and physiological variations. Endocrinology 107, 2088-2098. 
63. Zambrano E, Rodriguez-Gonzalez GL, Guzman C, et al. (2005) A maternal low protein diet during pregnancy and lactation in the rat impairs male reproductive development. J Physiol 563, 275-284.

64. Hartriyanti Y, Suyoto PS, Muhammad HF, et al. (2012) Nutrient intake of pregnant women in Indonesia: a review. Malays J Nutr 18, 113-124.
65. Lee SE, Talegawkar SA, Merialdi M, et al. (2013) Dietary intakes of women during pregnancy in low- and middleincome countries. Public Health Nutr 16, 1340-1353.

66. Stephens TV, Payne M, Ball RO, et al. (2015) Protein requirements of healthy pregnant women during early and late gestation are higher than current recommendations. $J$ Nutr 145, 73-78. 